\title{
CHISHOLM'S THEORY OF ACTION
}

\section{ALVIN I. GOLDMAN}

In any generation there are relatively few people who make major original contributions to even a single area of philosophy. But the man whose work is the topic of this conference has made such contributions not only in a single field, but in several. This morning and afternoon we have devoted our attention to Chisholm's epistemology, the breadth and significance of which is evident. Equally deserving of our attention, however, are his contributions to the theory of action and metaphysics, and we shall be turning to these topics this evening and tomorrow. As in epistemology, Chisholm's work in these areas has focused on the deepest philosophical problems. He has worked out suggested solutions to these problems with a scope, precision, and care which serve as models for others to emulate.

\section{Sketch of Chisholm's Position}

Chisholm's theory of action and agency begins, of course, with the question of freedom and determinism, or rather, as he formulates it, the problem of responsibility and determinism. The problem is that responsibility seems to conflict both with determinism and with indeterminism. It conflicts with determinism since an agent is responsible for an action only if he could have done otherwise; and he could have done otherwise only if his action was not causally determined by prior events, even internal events such as his own desires and beliefs. On the other hand, it conflicts with indeterminism as well. If the action is not caused at all, if it is fortuitous or capricious, merely happening "out of the blue," then again the agent cannot be responsible for it. Chisholm's solution is to distinguish between two kinds of causation: agent-causation and eventcausation. If a man is responsible for a deed, says Chisholm, there is some event that is not caused by other events and states of affairs, but is caused by the man or agent himself. Such an event is not 
causally determined by previous events, but neither is it wholly uncaused. This, says Chisholm, allows for ascriptions of responsibility.

Chisholm's theory of action, then, centers on his account of agent-causation. The locution he uses to express agent-causation, however, is introduced as a primitive, undefined expression. This is the expression ' $\mathrm{S}$ makes it happen that $\mathrm{p}$ in the endeavor to make it happen that q.' To grasp the theory he puts forward, one must examine the axioms that govern this locution, the way he uses it to define other expressions in our language of action and purpose, and the illustrations he gives of the applications of these expressions. ${ }^{1}$ There is little point, however, in my reviewing all of these axioms, definitions, and illustrations, or even very many of them, partly because they are doubtless familiar to most members of the audience and partly because any attempt to do justice to their richness would exceed the time which an after-dinner speaker should be accorded. Instead, let me try to sketch a picture of human action which I think emerges from Chisholm's definitions, illustrations, and announced philosophical motivation. In the course of this sketch I shall refer to a few of his definitions and axioms, but I make no pretense to completeness. Moreover, I shall sometimes give my own examples, and hazard conjectures about the reasons for certain moves which Chisholm himself may not give.

Let us begin with a simple case. Suppose that Smith's arm is paralyzed, but, unaware of this, Smith tries to raise his arm. What does this trying consist in? If I understand Chisholm's theory correctly, he would say that it consists in the following: Smith makes a certain neural event happen in the endeavor to make it happen that his arm rise. This example illustrates two features of Chisholm's agency locution. First, to say that $S$ makes it happen that $p$ in the endeavor to make it happen that $q$ entails that $S$ does make it happen that $p$; so $p$ obtains. Second, to say that $S$ makes it happen that $p$ in the endeavor to make it happen that $q$ does not entail that $q$ obtains. These principles are exemplified in our case: Smith does make it happen that the neural event occurs but, being paralyzed, his arm does not rise. The example also illustrates another feature of Chisholm's locution, viz., that $S$ can make $p$ happen in the endeavor to make $q$ happen without knowing or suspecting that he makes $p$ happen, and without intending or endeavoring to make $p$ happen. In our example, we suppose that Smith neither intends nor realizes that the neural event in question occurs (or that he makes it occur). 
Now let us turn to a second case. Suppose that Smith's arm is not paralyzed, and that he succeeds in making it rise. Suppose, moreover, that this deed of Smith's is one for which we think he is responsible. Then since responsibility precludes determinism, according to Chisholm, we must suppose that Smith's deed is not determined by prior events. Yet it seems clearly false to maintain that the rising of his arm is not causally determined by prior events; surely it is causally determined by such prior events as the contraction of certain muscles. Chisholm does not deny this. Rather, he construes Smith's deed or action as starting with the (first) neural event which he makes happen in the endeavor to make his arm rise. Although the rising of the arm is causally determined by prior events, this neural event is not so determined. It does not follow, of course, that the neural event is uncaused; on the contrary, it is caused by Smith himself. We have here a paradigm instance of pure agent-causation, unaccompanied by event-causation. Of course, neurophysiologists might contend that there are no cerebral events that are not determined by preceding events, any more than there are arm risings that are not causally determined by muscle contractings. But perhaps Chisholm does not claim that there actually are any instances of neural events which are caused by agents but not events. Perhaps he is only claiming that there are such events if we are ever responsible for our deeds. But he certainly appears to believe that we are sometimes responsible for our deeds.

At this point a clever critic might point out that although Chisholm's theory does not leave the neural event wholly uncaused - it being caused by Smith himself - there may yet be another wholly uncaused event, viz., Smith's making it happen that $p$ in the endeavor to make it happen that $q$. To forestall such an objection, Chisholm states it as an axiom that if $S$ makes it happen that $p$ in the endeavor to make it happen that $q$, then $S$ makes it happen that he makes it happen that $p$ in the endeavor to make it happen that $q$ in the endeavor to make it happen that $q .{ }^{2}$ (i.e., $M p, q \supset M(M p, q), q$. Here, as throughout, I omit temporal qualifiers in the interest of simplicity.) This axiom naturally has the consequence that there is an indefinitely large set of "nested" events each of which is agentcaused but presumably not event-caused. It is not clear that there is any a priori objection to such an infinite set of events.

Let us turn now to a third example. Suppose that Smith raises his arm for some further purpose, e.g., to catch the attention of his friend. Chisholm would render this situation as follows. ${ }^{3}$ Smith makes it happen that his arm rises in the endeavor to make it happen 
(1) that his arm rise, (2) that his friend's attention be caught, and (3) that his arm's rising cause (or causally contribute to) the friend's attention being caught. Thus, according to Chisholm, we can explain acting for a purpose in terms of two primitive notions, viz., (a) the notion of making something happen in the endeavor to make something (else) happen, and (b) event-causation.

Admittedly, not all cases of acting for a purpose can be handled as easily as the foregoing one. Chisholm, with his characteristic ingenuity, reminds us of a case which other theories of action have found difficult, and proceeds to show how his own theory can handle it. Suppose that Smith makes his arm rise for the purpose of making it happen that a certain muscle contract, or, as we might say, for the purpose of making it happen that a certain muscle "have contracted." This cannot be rendered by saying that Smith makes it happen that his arm rise in the endeavor that his arm's rising cause (or causally contribute to) the contracting of the muscle; for the contracting of the muscle precedes the rising of the arm, or at any rate causes it, and this is something which Smith knows and intends. Chisholm's rendering of this case is as follows. Smith makes it happen that his arm rise in the endeavor to make it happen (1) that his arm rise, (2) that the muscle contract, and (3) that his making something happen in the endeavor to make his arm rise should cause, or causally contribute to, the muscle's contracting. This solves the problem beautifully. For Smith does endeavor to make it happen that a certain endeavoring of his - the exact nature of which he may not know - should cause the contracting of the muscle. Since this endeavoring includes the occurrence of an earlier neural event, it is reasonable for Smith to have such an endeavor.

In numerous suggestive articles, Chisholm proceeds to explicate a large number of action expressions, using only the primitive locutions which we have mentioned (or slightly revised versions of these locutions). Among the expressions which he explicates are the following: ' $S$ intentionally causally contributes to its happening that $\mathrm{q}$,' ' $\mathrm{S}$ makes it happen that $\mathrm{q}$ and his doing so is a basic act,' ' $\mathrm{S}$ makes it happen that $\mathrm{q}$ and does so just in the way in which he intends,' and 'It is within S's power to undertake to make it happen that q.' A full appreciation of the richness of his theory requires an appreciation of his treatment of these locutions. But for present purposes, let us content ourselves with the sketch of the theory I have presented to this point. 


\section{The Concept of Agent-Causation}

In assessing the theory we must obviously assess the main distinctive concept to which Chisholm appeals, the concept of agentcausation. It is difficult to assess this concept, however, since Chisholm offers no definition or analysis of it. I am sure that many of his readers, myself included, are somewhat puzzled by this notion. As usual, Chisholm himself anticipates the puzzles or questions of his readers. One is inclined to ask, says Chisholm, what the difference is between the mere occurrence or happening of an undetermined event and its being caused by an agent. Chisholm replies that the only answer than can be given is that an event which merely happens is a completely uncaused event, whereas an event which is caused by an agent is not uncaused. ${ }^{4}$ But this reply is obviously not very satisfying. To say that the undetermined event is not uncaused is equivalent to saying that it is either event-caused or agent-caused. But, by hypothesis, it is not event-caused, so this comes down to saying that it is agent-caused; and this is precisely what we seek to have explained.

Chisholm seems to concede that the concept of agent- or immanent-causation is somewhat unclear. But he contends that it is no more unclear than the concept of event-causation. ${ }^{5}$ I find this contention unpersuasive. Though there is no universally accepted analysis of event-causation, a number of analyses have at least been undertaken, analyses that involve either natural laws, counterfactuals, or "conditions" of some sort. By contrast, nothing whatever has been offered by Chisholm, even as a rough or approximate explication of the concept of agent-causation. Now perhaps Chisholm's position is that the concept of agent-causation need not be explicated or analyzed in order to be understood. Perhaps he contends that we can understand this concept by a sort of introspection, even if this understanding cannot be articulated in the form of an analysis or definition. In this connection he approvingly quotes Thomas Reid to the effect that the concept of agentcausation is logically and epistemologically prior to that of eventcausation. ${ }^{6}$ Reid says: ". . . the conception of an efficient cause may very probably be derived from the experience we have had ..., of our own power to produce certain effects." I would reply to this by arguing that the experience of our power to produce effects is only the experience of the propensity of our desires or intentions to produce corresponding effects. Thus, contrary to what Reid and Chisholm maintain, the concept of the power of an agent is derivative from the concept of event-causation. 
There is, moreover, an apparent anomaly in the notion of pure agent-causation, and this anomaly must be explained away if the notion is to be legitimized. In every other case in which a substance is a cause, some event or state of affairs involving that substance is an event-cause of the same effect. (Notice that $I$ do not say, with Broad, that a statement ascribing causation to a substance is always an ellipsis for an event-causation statement.) When a stone is correctly said to be the cause of a window's breaking, there is some event or state of affairs involving the stone - e.g., its striking the window with a certain force or momentum - which is an eventcause of the window's breaking. But according to Chisholm, pure agent-causation is unaccompanied by event-causation. There appears to be an anomaly here that calls for explanation. Pending an explanation, one is entitled to be suspicious of the concept's legitimacy.

\section{Responsibility and Determinism}

If Chisholm's solution to the problem of responsibility leaves one unhappy or discontent, it is natural to try to retrace the steps that led to this proposed solution. In particular, one is inclined to reconsider the argument that suggested an incompatibility between responsibility and determinism. Chisholm maintains that a man is not responsible for an action unless he could have done otherwise, and that if the deed was causally determined by prior events, even such events as his own desires and beliefs, then he could not have done otherwise. The traditional reply by the reconciliationist, however, is that the statement "He could have done otherwise" is compatible with the truth of determinism. The reconcialiationist's main "strategem," as Chisholm presents the position, ${ }^{7}$ is to say that the expression

(A) He could have done otherwise means "no more nor less than"

(B) If he had chosen to do otherwise, he would have done otherwise.

This counterfactual can be true even though what he actually did was causally determined. Hence, it is argued, there is no incompatibility between determinism and responsibility.

Chisholm attacks this reconciliationist "strategem" by arguing that (B) is not a correct translation of (A). Suppose, he says, that statement 
(C) He could have chosen to do otherwise

is false. Then even though (B) is true, (A) will be false. But if there is a possible case in which (A) is false though (B) is true, then (B) doesn't entail (A). Hence (B) is not a correct translation of (A).

There are two rejoinders I wish to make to this argument. First, I suggest that we should not be too hasty in conceding that Chisholm's argument demonstrates that (B) is not a correct translation of $(A)$. Second, even if we do concede this point, it does not in the least follow that reconciliationism is mistaken, that responsibility is incompatible with determinism.

I take up the first point first. Is it clear that (A) must be false when (B) is true but (C) false? Surely this depends on the senses of 'could' in (A) and (C). It is clear enough that there are some senses of 'could' in which the falsity of (C) implies the falsity of (A), at least if we make a further assumption, viz., that his choosing to do otherwise is a (causally) necessary condition of his doing otherwise. Specifically, if (A) either means or implies "It was not causally determined that he not do otherwise," and if (C) means "It was not causally determined that he not choose to do otherwise," then the falsity of (C) implies tha falsity of (A) (at least if we make the further assumption mentioned a moment ago). But of course it cannot legitimately be assumed that (A) either means or implies "It was not causally determined that he not do otherwise," for this is one of the very points at issue.

Perhaps, in advancing the argument against the reconciliationist's "strategem," Chisholm thinks that in every sense of "could," the falsity of (C) implies the falsity of (A). He might be assuming a general modal principle, governing every use of "could," or at least every conceivably relevant use of 'could,' that if $\mathrm{Y}$ is a causally necessary condition for the occurrence of $X$, then the falsity of

(P) Y could have occurred

entails the falsity of

(Q) X could have occurred.

A bit of reflection reveals, however, that this is not true in general. Consider

(A') The sugar could have dissolved in the water.

Assume that the sugar's being immersed in the water is a causally necessary condition of the sugar's dissolving in the water. Nonetheless, it is not at all obvious that the falsity of 
(C') The sugar could have been immersed in the water entails the falsity of $\left(A^{\prime}\right)$. There seems to be at least one way of understanding $\left(A^{\prime}\right)$ such that its truth is compatible with the falsity of $\left(C^{\prime}\right)$. A standard way of interpreting $\left(A^{\prime}\right)$ is as

$\left(B^{\prime}\right)$ If the sugar had been immersed in the water, it would have dissolved.

On this interpretation, $\left(A^{\prime}\right)$ is compatible with the falsity of $\left(C^{\prime}\right)$. Thus, Chisholm cannot claim that the sort of entailment in question holds for every sense of "could" without running into conflict with one standard use of the phrase "could have." Unless he can show on independent grounds that this counterfactual sense of "could have" is not appropriate to the "could have" of agency, he is not entitled to assume that the falsity of (C) entails the falsity of (A).

However, let us grant for the sake of argument that (B) is not a correct translation of $(A)$, and for the very reason Chisholm gives, i.e., that (B) does not entail (A). Does it follow from this, as Chisholm seems to think, that responsibility is incompatible with determinism? Not at all. From the fact that this one attempted translation of (A) fails it does not follow that all other reconciliationist attempts to translate (A) would fail. Although (B) may not be equivalent to (A), there may be another statement compatible with determinism which is equivalent to (A). Indeed, although (B) itself is not equivalent to (A), it may be one conjunct of a conjunction that is equivalent to (A). Indeed, as far as Chisholm's argument goes, it could turn out that (A) is equivalent to the conjunction of (B) and (C). To be sure, if such a conjunction is to save the day for the reconciliationist, he must make out the claim that the "could" in (C) is compatible with determinism. (C) must not mean or imply "It was not causally determined that he not choose to do otherwise." But this is certainly an open possibility, which Chisholm has not eliminated. Thus, Chisholm has not really established that there is no correct reconciliationist translation of (A). At most he has shown, what many people are prepared to grant, that (B) by itself is not a correct translation of (A).

\section{Responsibility and Agent-Causation}

Defenders of reconciliationism have typically been on the defensive against arguments of the sort Chisholm presents. If I may be allowed a football metaphor, a lot of "playing time" is spent with the reconciliationist near his own goal line, trying to protect it 


\section{CHISHOLM'S THEORY OF ACTION}

against the assaults of his foes. Occasionally, it is true, he mounts an offensive. For example, he contends against the indeterminist that actions which are wholly uncaused or fortuitous cannot be responsible. But this will not work against Chisholm, who claims that actions are caused, but only caused by agents.

What I shall now try to do is launch a more concerted offensive against Chisholm's account. I shall argue that Chisholm's combination of agent-causation but not event-causation yields a thoroughly unsatisfactory treatment of responsibility.

Let me first point out that many statements of responsibility are future-oriented. In the debate over free will, philosophers have focused too heavily on backward-looking ascriptions of responsibility, and this emphasis, I think, is misplaced. We often make someone responsible for bringing about a certain future event, or for performing a future action. We charge him now, for example, with the responsibility of getting the dishes washed before the company arrives, or with locking the building when everyone has gone home. Such assignments of responsibility are widely regarded as reasonable and in order, even by those to whom such responsibility is given. But would such assignments of responsibility be in order if Chisholm's theory of action were true, that is, if actions were never caused by events or states of affairs? I think not. (It is not quite accurate to say that, according to Chisholm, actions are never caused by events or states of affairs. He admits that desires sometimes necessitate actions. On these occasions, however, Chisholm would say that the agent is not responsible for his actions. Since we are only interested in cases where the agent is responsible, and since, according to Chisholm, these are cases where the actions are not caused by events or states of affairs, I shall assume for simplicity that, according to Chisholm, no actions are caused by events or states of affairs.)

Suppose that Smith is responsible for performing action $\mathrm{A}$ at a future time t. Smith believes, however, and has good reason to believe, that no matter what plans or intentions he forms to do action $A$, there will be no grounds for believing that he will succeed in performing it. No matter what preliminary steps he takes, no matter what forethought and devotion he gives to it, he has no reason to think he will succeed in doing it. In particular, suppose that Smith believes (and has good reason to believe) that whether or not action $A$ is performed does not depend on any of his intentions, either prior to $t$ or at $t$. There is no reason to believe that an intention to do A, either prior to $t$ or at $t$, will lead to, or result in, his doing A. Furthermore, suppose that Smith knows that whether or 
not action $\mathrm{A}$ is performed depends on some powerful and alien force, which would not and could not be affected by any of his plans or intentions. No matter what Smith's intentions might be, this powerful force could see to it that an entirely different action would be performed. If Smith knew these things, I suggest, he would feel very insecure about his position. He has been charged with executing a certain task. He feels an obligation to do it, perhaps, and fears penalties for non-fulfillment. But the matter appears to be entirely out of his hands, beyond his control. It would be natural for Smith, in such a situation, to seek to be relieved from his responsibility; and a sympathetic observer would surely support such a plea on his part. It would be unreasonable, in the circumstances, to hold Smith responsible for executing the task in question.

Now I wish to argue that if Chisholm is right about action and agency, that if no actions are ever event-caused, but are only agentcaused, then anyone charged with an obligation would essentially be in Smith's situation. But in this kind of situation it is unreasonable to hold a person under an obligation, to make him responsible. Hence, Chisholm's theory is incompatible with responsibility, at least the forward-looking kind of responsibility that $I$ have been discussing.

What is my reason for saying that, if Chisholm is right, we are always in Smith's situation? Well, according to Chisholm, no action is ever caused by events or states of affairs. It follows from this that they are never caused by the agent's intentions or choices, which are events or states of affairs. It is true that Chisholm uses such locutions as "S acts with the intention of bringing about a." But this is talk of acting with an intention, not acting as a result of an intention. As far as I can see, the fact that $S$ has a current intention, or has had a past intention, to do action $\mathbf{A}$ at this moment is no reason at all to think that he will do $\mathrm{A}$ at this moment. Whether or not he does $\mathrm{A}$ is causally dependent only on an agent, and hence not at all, according to Chisholm, on a state of affairs such as an intention. If the agent causes him to act in a way that accords with the intention, then presumably he will have acted with that intention. But, given that he has that intention, it is still entirely open to the agent to cause him to act quite contrary to that intention. The intention itself in no way determines what the action will be.

Now in describing Smith's situation, I spoke of Smith's action as being dependent on a powerful and "alien" force. Is this a legitimate expression to use? Chisholm would doubtless reject it as inappropriate. The "force" on which action depends is not at all "alien," 
Chisholm would hasten to say, but Smith himself! How can Smith himself be an "alien" force?! My reply to this - which I can only sketch here, and not defend in detail - is that the denial of causal relations between intentions and actions serves to undermine our notion of the self and of personal identity over time. I would contend that the notion of identity of an object over time partly involves the presupposition that earlier states of the object make causal contributions to its later states. The sense one has of one's self as a continuing entity presupposes the idea that one's present mental states should have some causal effect on future mental states, and that these in turn should have causal effects on one's action. To deny the causal dependence of one's actions on one's choices and intentions, either present or preceding, is to do violence to our conception of the self as an agent. If these causal dependences are severed, as Chisholm's theory would apparently sever them, I have doubts that we could recognize the self in the wreckage. Certainly I cannot feel confident that Smith's present self, which now intends to do a certain later action, is or will be identical with that so-called "agent" which Chisholm says will be the cause of future action, quite independent of any desires or intentions that crop up at any point during this period.

It is worth pointing out that Chisholm's own definition of intention, which appears in an article not dealing with the metaphysics of agency, seems to run afoul of his own theory of agency. In the 1970 paper, "The Structure of Intention," Chisholm offers the following definition:

$S$ has the intention at $t$ of bringing it about that $q=d f$

At a time prior to $t S$ intended something as a preliminary step toward his bringing it about that $\mathrm{q}$, and from that time on he has confidently believed that he will make an attempt to bring it about that $q$ and that he will succeed. ${ }^{8}$

When I say that this definition "runs afoul" of Chisholm's own theory of agency, I do not mean that the definition cannot be satisfied if his theory of agency is correct. I mean something slightly weaker. I mean that if a person is rational, and if he accepts Chisholm's theory of action and agency, then he will never satisfy the definition, for he will never have an intention, according to the definition. To see why, consider the second part of the definition, which says that $S$ confidently believes that he will make an attempt to bring it about that q. If S accepts Chisholm's theory of action and 
agency, he will not be justified in confidently believing that he will make any particular attempt in the future. The only thing that could justify such confidence is some belief about the causal connection between present states of affairs and future actions (or attempts). But since, according to Chisholm's theory, no future action (at least no responsible action) would be caused by present states of affairs, there would never be any justification for such confidence. Hence, a rational person would not have such confidence, and therefore, according to the definition, would not have any intention.

For the same reasons that a (rational) man will never intend anything, according to Chisholm's theory, he will also never engage in deliberation. The only point of deliberation is to form a current intention, on the presupposition that this intention will bring about future action. But if Chisholm's theory is correct, there will never be any grounds for this presupposition, and hence no rational person will engage in deliberation. We see, then, that Chisholm's theory, so far from preserving the possibility of responsibility, intention, and deliberation, has the effect of undermining the possibility of such states of affairs.

\section{Causal and Non-Causal Connections}

Until now I have been arguing that Chisholm makes too little use of event-causation: his denial of event-causation for a certain range of phenomena yields a theory of action that conflicts with certain desiderata for such a theory. I wish now, however, to tum to a different point. What $I$ wish to argue is that Chisholm tries, in a certain part of his theory, to make too much use of event-causation.

It should be noted that the foregoing points which I raised concentrated on certain global features of Chisholm's theory. This is not only because these global features are important, nor because it is those features of the theory with which I most disagree, but also because it is so difficult to criticize the details of Chisholm's theory. As always, Chisholm has developed his theory with precision and attention to detail. His development of the fundamental philosophical ideas is carried out with great subtlety and thoroughness. Hence, there are relatively few points of detail on which to fault him, at least that I can find. Nonetheless, let me mention one relatively minor problem which I think his theory does not handle adequately. 
The problem I have in mind concerns the analysis of the concept of adopting one state of affairs as a means to another state of affairs. We saw earlier that Chisholm tries to analyse the locution ' $S$ makes $p$ happen with the purpose of making q happen' with the use of only two primitive concepts: (1) making something happen in the endeavor to make something happen, and (2) event-causation. Now in the 1970 paper on intention, he uses a slightly different primitive locution, but since I am not concerned with that difference, let me stick with the older one. He proceeds to give a definition of 'S acts with the intention of bringing it about that $\mathrm{q}$ and does so in order that q.' This definition closely parallels the characterizations of making something happen with a purpose, which we discussed earlier. A bit later Chisholm proposes to define the notion of adopting one state of affairs as a means to another. What he says is that when a man intends to bring about one state of affairs in order that another state of affairs may obtain, then we may also say that the first state of affairs is itself a means to the second provided that the agent believes that it (the first state of affairs), as distinguished from his bringing it about, will causally contribute to the second. ${ }^{9}$ What I wish to argue now is that this definition is too narrow for Chisholm's purposes, and the reason it is too narrow is that he restricts himself to causal contribution.

The worry I have can be identified with the following example. Suppose Smith extends his arm out the car window in order that he signal for a turn. It seems natural to me to say, in addition, that Smith adopts the first state of affairs, viz., his extending his arm out the window, as a means to the second, viz., his signaling for a turn. But the condition or analysis Chisholm suggests does not cover this case. For if we may assume that Smith is rational, he will not believe that the state of affairs which consists in his extending his arm out the car window will causally contribute to the state of affairs which consists in his signaling for a turn. The relation between these two states of affairs (or, more precisely, between the obtainings of these states of affairs) would not be causation, or causal contribution. This seems to me evident on the face of it. But if any arguments are needed, I might point out, first, that there is no law of nature that would connect expending one's arm with signaling for a turn, and, second, that if these states of affairs were to obtain they would obtain simultaneously, which appears to rule out causal connection.

To handle this case, I think that Chisholm needs to expand his concept of the sorts of ways states of affairs can be related to one another, or, more precisely, the ways their obtainings can be related 
to one another. The notion of a conventional connection is what seems to be required to handle the signaling case. But other kinds of connections must be countenanced to handle other kinds of cases. I have attempted to work out such non-causal concepts in another context, and shall not repeat those suggestions here. ${ }^{10}$ I will content myself with the simple point that Chisholm cannot succeed in doing everything he wants to do if he confines himself to the two resources he selects, viz., one of his primitive teleological locutions and the concept of event-causation. But to say that he cannot do everything he wants to do with these resources is not to deny the impressive amount of territory he has been able to cover with these resources, nor to minimize the importance of that achievement.

THE UNIVERSITY OF MICHIGAN ANN ARBOR, MICHIGAN 48109

USA

\section{NOTES}

1 The main articles in which Chisholm's theory is developed are the following (the indicated abbreviations will be used in the remaining footnotes): "Freedom and Action" (FA), in Keith Lehrer, ed., Freedom and Determinism, New York: Random House (1966); "Some Puzzles About Agency" (SPAA), in Karel Lambert, ed., The Logical Way of Doing Things, New Haven: Yale University Press (1969); "On the Logic of Intentional Action" (LIA), in Robert Binkeley, et al., eds., Agent, Action and Reason, Toronto: University of Toronto Press (1971); and "The Structure of Intention" (SI), The Journal of Philosophy, LXVII, No. 19 (October 8, 1970), pp. 633-647.

See SPAA, p. 206, and LIA, p. 47.

3 See FA, pp. 35-36, and LIA, pp. $55 \mathrm{ff}$.

4 See FA, p. 21.

5 Ibid., p. 22.

6 Ibid., p. 22.

7 Ibid., pp. $14 \mathrm{ff}$.

8 SI, p. 646.

9 Ibid., pp. 638-639.

10 See A Theory of Human Action, Princeton: Princeton University Press (1977), Chapter 2. 